\title{
Amniotic fluid macrophages and the antenatal diagnosis of anencephaly and spina bifida
}

\author{
GRANT R. SUTHERLAND,* D. J. H. BROCK, and J. B. SCRIMGEOUR \\ Department of Pathology, Royal Hospital for Sick Children and University of Edinburgh, and the \\ Departments of Human Genetics and Obstetrics and Gynaecology, University of Edinburgh
}

\begin{abstract}
Summary. The macrophage content of amniotic fluid has been measured and the upper limit of normal on an arbitrary scale is 41 . Amongst 65 amniotic fluids collected for antenatal diagnostic studies before 22 weeks' gestation there were eight which had macrophage counts ranging from 82 to 6226 , three of these were shown to have anencephaly and two spina bifida. The reasons for three apparently false positives are as yet undetermined. Rhesus iso-immunized amniotic fluids were found to have macrophage counts of up to 276 and a possible explanation for this is considered. It is argued that an elevated amniotic fluid macrophage count may indicate a CNS defect or possibly other fetal abnormality.
\end{abstract}

The finding by Sutherland, Brock, and Scrimgeour (1973) of large numbers of macrophages in the amniotic fluid from two cases of anencephaly has been used by Nelson, Ruttiman, and Brock (1974) to make the antenatal diagnosis of a further case. The macrophage content of spina bifida and anencephalic amniotic fluids has been quantitated and compared with that from normal pregnancies.

\section{Materials and methods}

Amniotic fluids were obtained by amniocentesis for antenatal chromosome studies, $\alpha$-fetoprotein estimation, during the management of Rhesus iso-immunized pregnancies and at induction of labour in cases where the fetus was known to have anencephaly.

Amniotic fluid cultures were established as previously described (Sutherland, Grace, and Bain, 1973). The culture vessel was a $50 \mathrm{~mm}$ Petri dish which contained five or six $6 \times 22 \mathrm{~mm}$ glass coverslips. The culture medium was Ham's F10 supplemented with $30 \%$ fetal calf serum. The day after cultures had been set up (usually about 20 hours later) one of the coverslips was aseptically removed from the Petri dish, washed well in phosphate buffered saline, fixed with methanol, stained with Giemsa, and mounted on a slide. The number of glass adherent cells in 10 low power fields $(x 100)$ were

Received 21 June 1974.

* Present address and reprint requests to: Cytogenetics Unit, Department of Pathology, The Adelaide Children's Hospital, North Adelaide 5006, Australia. counted and this number was adjusted to relate to $10 \mathrm{ml}$ of amniotic fluid, ie, if the cells from $5 \mathrm{ml}$ of amniotic fluid had been inoculated into the Petri dish then the number was multiplied by two. The resultant macrophage count (glass adherent cells/10 low power fields/ $10 \mathrm{ml}$ of amniotic fluid) has been used to compare different samples of amniotic fluid. Amniotic fluid $\alpha-$ fetoprotein was measured according to Brock and Sutcliffe (1972).

\section{Results}

The macrophage counts for the 94 fluids studied are shown in Fig. 1. All the fluids classed as 'normal' had low macrophage counts (range 0-41), and there was no reason to suspect fetal CNS abnormality either because the infant had been delivered or because the amniotic fluid $\alpha$-fetoprotein levels were not elevated. Four amniotic fluids from cases of hydramnios of unknown aetiology had macrophage counts within the normal range. A number of samples of amniotic fluid showing different degrees of blood staining had normal macrophage counts. Rhesus iso-immunized amniotic fluids had highly variable macrophage counts ranging up to 276. Where serial samples were obtained from these pregnancies the macrophage counts tended to decrease as gestation progressed.

Details of the cases with anencephaly or spina bifida are shown in Table I. In all except one of these fluids the macrophage count was elevated, 


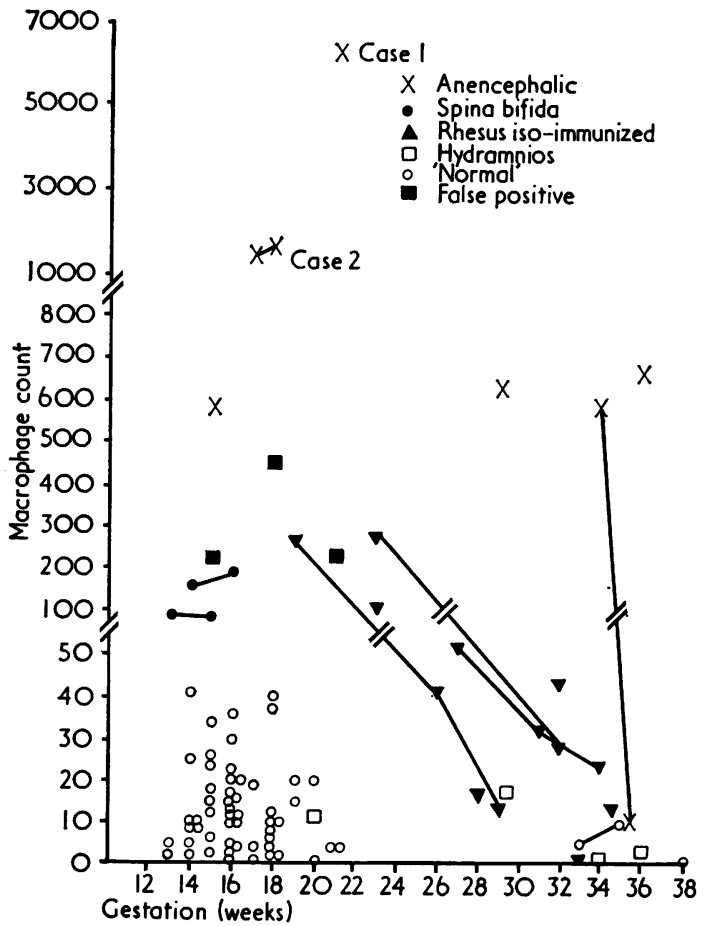

FIg. 1. Macrophage counts of amniotic fluids in this study in relation to gestation. Cases 1 and 2 have been previously reported (Sutherland et al, 1973a).

TABLE I

DATA PERTAINING TO EIGHT CASES WITH CNS ABNORMALITIES IN THIS STUDY

\begin{tabular}{|c|c|c|c|c|}
\hline $\begin{array}{l}\text { Case } \\
\text { No. }\end{array}$ & $\begin{array}{l}\text { Gestation } \\
\text { (weeks) }\end{array}$ & $\begin{array}{c}\text { Macrophage } \\
\text { Count }\end{array}$ & $\underset{(\mu \mathrm{g} / \mathrm{ml})}{\alpha-F e t o p r o t e i n}$ & CNS Lesion* \\
\hline $\begin{array}{l}1 \\
2 \\
3 \\
4 \\
5 \\
6 \\
7 \\
8\end{array}$ & $\begin{array}{l}21 \\
17 \\
18 \\
36 \\
33 \\
35 \\
29 \\
15 \\
14 \\
16 \\
13 \\
15\end{array}$ & $\begin{array}{r}6226 \\
1540 \\
1640 \\
660 \\
590 \\
10 \\
630 \\
576 \\
168 \\
189 \\
82 \\
84\end{array}$ & $\begin{array}{r}238 \\
254 \\
250 \\
6.4 \\
26 \\
21 \\
44 \\
680 \\
181 \\
173 \\
143 \\
118\end{array}$ & $\begin{array}{c}\text { ASB } \\
\text { ASB } \\
\text { ASB } \\
\text { ASB } \\
\text { ASB } \\
\text { ASB } \\
\text { SB } \\
\text { SB }\end{array}$ \\
\hline
\end{tabular}

- ASB = anencephaly and spina bifida; $\mathrm{SB}=$ spina bifida.

ranging from 82 to 189 for the spina bifida fluids and from 576 to 6226 for the anencephalics. The fluid in which the macrophage count was not elevated was the second sample received from a twin pregnancy in which one of the twins was normal and the other anencephalic. Details of this case are shown in Table II.

There are three cases, listed as 'false positive' in Fig. 1 which are a problem in that they had elevated macrophage counts and normal $\alpha$-fetoprotein
TABLE II

DATA ON AMNIOTIC FLUIDS FROM THE TWIN PREGNANCY IN WHICH ONE TWIN WAS ANENCEPHALIC

\begin{tabular}{c|c|c|c|c}
\hline Twin & $\begin{array}{c}\text { Gestation } \\
\text { (weeks) }\end{array}$ & $\begin{array}{c}\alpha \text {-feto- } \\
\text { protein } \\
(\mu \mathrm{g} / \mathrm{ml})\end{array}$ & $\begin{array}{c}\text { Macrophage } \\
\text { Count }\end{array}$ & $\begin{array}{c}\text { Chromo- } \\
\text { somal } \\
\text { Sex }\end{array}$ \\
\hline $\begin{array}{c}\text { I } \\
\text { (anen- } \\
\text { cephalic) }\end{array}$ & 33 & 26 & 590 & Female \\
\hline $\begin{array}{c}\text { II } \\
\text { (normal) }\end{array}$ & 35 & 21 & 10 & Female \\
\hline
\end{tabular}

levels. These pregnancies were allowed to continue and the one which had the highest macrophage count went into premature labour at 33 weeks' gestation and resulted in a normal male infant. The placenta showed multiple recurrent infarctions, there was a small succenturiate lobe and the cord had many false knots. The two other similar pregnancies are continuing.*

The possibility that interfering with the amniotic fluid cultures on the day after they have been set up may affect their success was tested by comparing the times required to achieve cytogenetic results from the first 25 normal cultures on which macrophage counts were performed (mean 13.0 days) with the 20 similar cultures studied before macrophage counts were being done routinely ( 14.5 days). In all cases where a cytogenetic result was required after macrophage counts had been performed this was achieved. It was not possible to differentiate between amniotic fluids with normal and raised macrophage counts (except in those cases where the macrophage count was grossly elevated) by direct inspection of the cultures with the inverted microscope. Quantitation of stained material was necessary for this purpose and its preparation did not prejudice the success of the cultures in any way.

\section{Discussion}

The antenatal diagnosis of anencephaly and spina bifida can be achieved with a high degree of success using amniotic fluid $\alpha$-fetoprotein measurements (Lancet, 1974). Ideally all samples of amniotic fluid, collected for any reason before mid-pregnancy, should have $\alpha$-fetoprotein estimations carried out. The two cases of spina bifida in this report were diagnosed from amniotic fluids collected primarily for antenatal chromosome studies.

The nature and origin of the glass-adherent cells in the amniotic fluid must be considered before their clinical relevance is discussed. All the glassadherent cells in amniotic fluid are probably not macrophages but erythrophagocytic properties

\footnotetext{
* These subsequently led to the birth of full-term normal infants.
} 
(Sutherland et al, 1973a) and ultrastructural studies (G. R. Sutherland, unpublished observations) have shown that at least a proportion of them are. In the cases where there is an open CNS lesion there are two likely sources of the macrophages. The CSF is in free communication with the amniotic fluid and the CSF is known to contain macrophages (Greenfield and Carmichael, 1925; Chester, Penny, and Emery, 1971). In these cases with open lesions there is considerable exposure of highly vascularized tissue, with only a membrane between the fetal circulation and the amniotic fluid; this should present little hindrance to the passage of circulating macrophages into the amniotic fluid. In the absence of a fetal lesion the origin of the macrophages is unclear, however cytological (Casadei et al, 1973) and ultrastructural (Hoyes, 1968) studies of normal amniotic fluid have revealed the presence of macrophages. The finding of increased macrophage counts in Rhesus iso-immunized amniotic fluids is of interest since an increase in placental macrophages (Hofbauer cells) has been described in this condition (Fox, 1967). In the Rhesus iso-immunized fetus there is an increase in extramedullary haemopoiesis (Morison, 1961), hence it is possible that an increase in circulating macrophages could be responsible for the increase in both the Hofbauer cells and the amniotic fluid macrophages. The mechanism of escape of the macrophages into the amniotic fluid is unknown but migration via the lungs and kidney tubules are possibilities.

There are a number of conditions which might lead to elevated amniotic fluid macrophage counts. Such conditions could include any fetal lesion which is not covered with skin, apart from the CNS defects exomphalos is one possibility. Conditions other than Rhesus iso-immunization in which there is increased extramedullary haemopoiesis such as the chondrodystrophies (Potter, 1961) and intra-uterine infection (Bain et al, 1956) might be expected to show an increase in amniotic fluid macrophages.

Macrophage counts would appear to be of value in two circumstances. Firstly, as an independent confirmation of an antenatal diagnosis based on $\alpha$ fetoprotein levels; this may be particularly helpful if $\alpha$-fetoprotein levels are equivocal. Second, where $\alpha$-fetoprotein is not being routinely measured on amniotic fluids which are collected for other purposes a raised macrophage count would be a strong indication that $\alpha$-fetoprotein levels should be estimated. There have been no false negative results in this series except for the unaccountable finding from the second sample from the twin pregnancy. Hence it appears unlikely that the macrophage count would be normal in cases of open fetal CNS defects. The main problem appears to be false positive results, the proportion of which will depend on the local incidence of CNS lesions. In the present series there were eight out of 65 amniotic fluids of less than 22 weeks' gestation examined blindly which had elevated macrophage counts and five of these proved to have open CNS lesions. Perhaps macrophage counts greater than 500 will prove to be diagnostic of anencephaly but at present it would be unwise to diagnose fetal abnormality on the basis of a raised macrophage count alone.

Further studies of the macrophages in amniotic fluid are required to assess fully the usefulness of this parameter in antenatal diagnosis. The false positives require special attention to try and determine whether they are of any significance. It may well be that a raised amniotic fluid macrophage count is a non-specific indication that all is not well with the fetus.

We would like to thank the obstetricians who provided some of the samples of amniotic fluid included in this study, especially Drs M. J. Butterworth, G. Gordon, A. M. Khan, and Professor J. S. Scott; Dr J. G. Robertson provided the Rhesus iso-immunized samples; Miss Sandra Brown assisted with the $\alpha$-fetoprotein determinations. We are grateful to Dr A. D. Bain for his helpful criticism during the preparation of this report. D.J.H.B. acknowledges support from the Association for Spina Bifida and Hydrocephalus.

\section{REFERENCES}

Bain, A. D., Bowie, J. H., Flint, W' F., Beverley, J. K. A., Beattie, C. P. (1956). Congenital toxoplasmosis simulating haemolytic disease of the newborn. Fournal of Obstetrics and Gynaecology of the British Empire, 63, 826-832.

Brock, D. J. H. and Sutcliffe, R. G. (1972). Alpha-fetoprotein in the antenatal diagnosis of anencephaly and spina bifida. Lancet, 2, 197-199.

Casadei, R., D'Ablaing, G., Kaplan, B. J., Schwinn, C. P. (1973). A cytologic study of amniotic fluid. Acta Cytologica, 17, 289-298.

Chester, D. C., Penny, S. R., and Emery, J. L. (1971). Fat-containing macrophages in the cerebrospinal fluid of children with hydrocephalus. Dezelopmental Medicine and Child Neurology, 13, Suppl. No. 25, 33-39.

Fox, H. (1967). The incidence and significance of Hofbauer cells in the mature human placenta. Fournal of Pathology and Bacterio$\log y, 93,710-717$.

Greenfield, J. G. and Carmichael, E. A. (1925). The Cerebro-Spinal Fluid in Clinical Diagnosis. MacMillan, London.

Hoyes, A. D. (1968). Ultrastructure of the cells of the amniotic fluid. Fournal of Obstetrics and Gynaecology of the British Commonwealth, 75, 164-171.

Lancet (1974). Towards the prevention of spina bifida. (Leader.) Lancet, 1, 907.

Morison, J. E. (1961). Foetal and Neonatal Pathology. Butterworth, London.

Nelson, M. M., Ruttiman, M. T., and Brock, D. J. H. (1974). Predictive value of amniotic-fluid macrophages in gross C.N.S. defects. Lancet, 1, 504.

Potter, E. L. (1961). Pathology of the Fetus and Infant, 2nd edition. Year book Medical, Chicago.

Sutherland, G. R., Brock, D. J. H., and Scrimgeour, J. B. (1973a) Amniotic fluid macrophages and anencephaly. Lancet, 2, 10981099.

Sutherland, G. R., Grace, E., and Bain, A. D. (1973b). Metaphase chromosomes from neonatal urine. Humangenetik, 17, 273-275. 